\title{
The use of mobile phone for seeking health care service or advice among women in Bangladesh: a cross-sectional study
}

\author{
Md Mosharaf Hossain ${ }^{1}$, Dr Ruhani Mat Min ${ }^{1}$, and Madihah Mohd Shukri ${ }^{1}$ \\ ${ }^{1}$ Universiti Malaysia Terengganu
}

August 5, 2020

\begin{abstract}
Objectives- The aim of this study is to identify socio-demographic and the use of basic maternal health care services associated with mobile use to receive health care services (antenatal care, transport in the facility and postnatal care for mother and newborn). Design- This a cross-sectional study Setting- Data were collected from eight districts in Bangladesh- Barishal, Chattogram, Dhaka, Mymensingh, Khulna, Rajshahi, Rangpur, and Sylhet by Bangladesh Demographic and Health Survey (BDHS) 2014 Sample- 4494 women aged 14-49 with children were involved in the research. Methods-Data were collected using questionnaire. Models of logistic regression were used for association determination. Results- The total woman using the mobile phone was reported $22.23 \%$. Among those $29.9 \%$ using the mobile phone to obtain health service or advice and $70.1 \%$ did not obtain health information. Women who had higher education with a mobile phone to received more health care (secondary and higher: $\mathrm{OR}=1.922,95 \% \mathrm{CI}=1.225-3.014$; primary: $\mathrm{OR}=1.982,95 \% \mathrm{CI}=1.738-2.654$ ), socio-economic status (rich: $\mathrm{OR}=1.228$, 95\% CI=1.009-1.494; middle: $\mathrm{OR}=1.691,95 \% \mathrm{CI}=1.256-2.333$ ), prenatal care (yes: $\mathrm{OR}=1.993,95 \% \mathrm{CI}=1.425-1.987)$, antenatal care (yes: $\mathrm{OR}=1.951,95 \% \mathrm{CI}=1.765-1.998$ ) and after delivery to check up health status (yes: $\mathrm{OR}=1.966,95 \% \mathrm{CI}=1.639-2.357$ ). Conclusions- The results of this study showed that women who have completed higher education, high-income families, young age groups, residence in urban areas are more likely to use mobile phones to receive health care facilities in Bangladesh. Intervention studies are essential for recognizing the instrument by which mobile phone-based facility improves maternal health care application.
\end{abstract}

\section{Hosted file}

Full Article.docx available at https://authorea.com/users/348950/articles/474128-the-useof-mobile-phone-for-seeking-health-care-service-or-advice-among-women-in-bangladesh-across-sectional-study 